\title{
Atmospheric instability analysis and its relationship to precipitation patterns over the western Iberian Peninsula
}

\author{
S. Queralt ${ }^{1}$, E. Hernandez ${ }^{1}$, D. Gallego ${ }^{2}$, and I. Iturrioz ${ }^{1}$ \\ ${ }^{1}$ Universidad Complutense de Madrid, Madrid, Spain \\ ${ }^{2}$ Universidad Pablo de Olavide, Sevilla, Spain
}

Received: 18 July 2006 - Revised: 28 January 2007 - Accepted: 30 January 2007 - Published: 26 April 2007

\begin{abstract}
Thermodynamic and dynamic atmospheric stability indices will be analysed in order to classify the rainfall types occurred in western Iberia and provide information about the associated meteorological phenomena and preferred regional instability sources. In this work, instability sources over the western Iberian Peninsula will be characterised by means of radiosonde station data and reanalysis data sets from the European Centre for Medium-Range Weather Forecasts (ECMWF), for the period 1971-2002. Dynamic stability indices such as the $\boldsymbol{Q}$ vector divergence $(d \boldsymbol{Q})$ or the potential vorticity anomaly in the $330 \mathrm{~K}$ isentropic surface $(P V)$ have been calculated with the aim of establishing different atmospheric stability scenarios. Furthermore, thermodynamic atmospheric stability contribution has been also evaluated with Total Totals index $(T T)$ and moisture availability was inferred from circulation weather types (CWTs). The first results of this work assess the combined dynamic-thermodynamic preferred conditions, synoptic situations and humidity sources, leading to precipitation events over the western Iberian Peninsula and prove the essential role of CWT patterns on the rainfall genesis.
\end{abstract}

\section{Introduction}

The atmospheric stability indices derived from daily radiosonde observations are considered representative of the synoptic-scale environment (Davis et al., 1997). They are usually derived from the Integrated Global Radiosonde Archive (IGRA) which is the largest and most comprehensive dataset of quality-assured radiosonde observations (Durre et al., 2006). In a recent work, stability indices derived from radiosonde data has been transformed into climatological variables to assess the variability of severe weather

Correspondence to: S. Queralt

(queralt@fis.ucm.es) potential (Derubertis et al., 2006). Other studies estimate water vapour trends (Ross and Elliot, 1996; Kassomenos et al., 2006) or temperature trends (Randel et al., 2005) from radiosonde dataset. Stability indices are usually employed to measure the ability of the atmosphere to develop severe weather or thunderstorm activity (Van Delden, 2003). The indices based on the energetic and thermal properties of the atmosphere account for the thermodynamical instability, while those founded on the velocity or geopotential heights quantify the dynamical instability. Both dynamic and thermodynamic analyses are usually insufficient to fully explain the origin of precipitation events. It is also necessary to take into account the water vapour availability in the atmosphere, the location of the moisture sources and the dominant air fluxes. In this regard, the synoptic processes involved on instability extreme episodes can be monitored by determining humidity transport (Dai et al., 1999) or analyzing the CWTs affecting an area. Recently, Trigo et al. (2000) and Paredes et al. (2006) developed the CWTs classification for Western Iberia and, along with its associated humidity transport (see Table 1).

The aim of this work is to combine two kind of analysis usually performed separately in a given area. First, to characterise the thermodynamic/dynamic atmospheric instability for Western Iberian by using several instability indices and second, to relate this information with the humidity transport and the prevalent synoptic conditions based on a CWT analysis.

\section{Data set and Methodology}

\section{$2.1 \quad$ Data}

Two daily radiosondes (00:00 UTC and 12:00 UTC) from IGRA have been used at four stations along the Western Iberian. They represent the Atlantic coastline facade; the

Published by Copernicus GmbH on behalf of the European Geosciences Union. 
Table 1. The ten classes of CWTs (Trigo et al., 2000) and associated humidity transport in western Iberia.

\begin{tabular}{lccl}
\hline CWTs & $\mathrm{N}^{\circ}$ & Symbol & $\begin{array}{l}\text { Associated flux } \\
\text { in western Iberia }\end{array}$ \\
\hline Anticyclonic type & 33 & A & Variable \\
Cyclonic type & 32 & C & Wet \\
Northeasterly type & 11 & NE & Dry \\
Easterly type & 12 & E & Dry \\
Southeasterly type & 13 & SE & Dry \\
Souhterly type & 14 & S & Dry \\
Southewesterly type & 15 & SW & Wet \\
Westerly type & 16 & W & Wet \\
Northwesterly type & 17 & NW & Variable \\
Northerly type & 18 & N & Variable \\
\hline
\end{tabular}

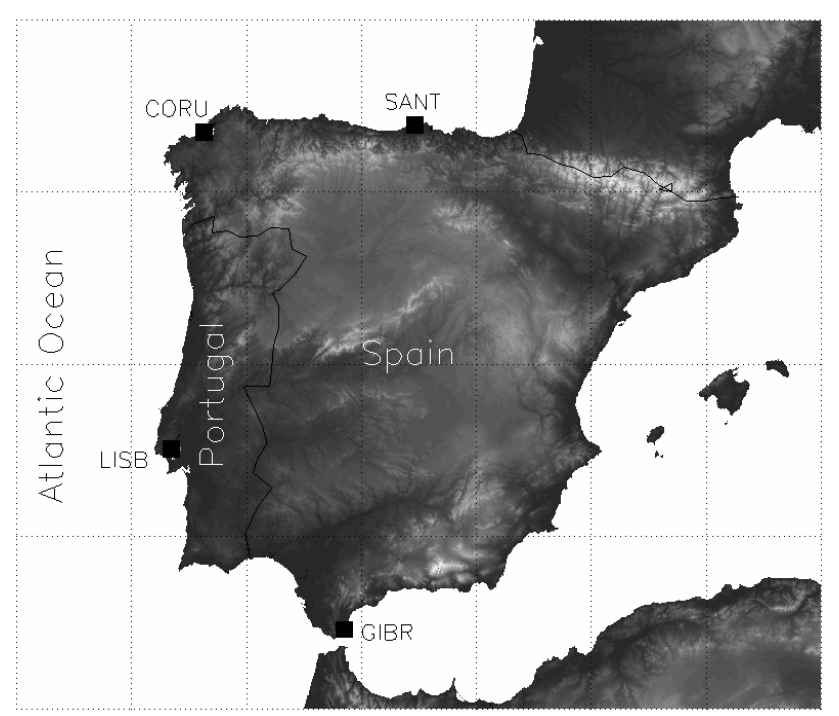

Fig. 1. Localization of the radiosonde stations in the study area.

stations are (from south to north): Gibraltar (GIBR), Lisboa (LISB), Santander (SANT) and A Coruña (CORU) (Fig. 1). The homogeneity of the series was assessed using the Lanzante method (1996) and the data quality controls of Wallis (1998) and Ross et al. (2001). The study period is 19712002 for all radiosonde stations except SANT, where dataset begins in 1986. The synoptic situations have been characterised by using the ERA40 reanalysis (horizontal and vertical velocity components, temperature and geopotential height) over an area comprised from $15^{\circ} \mathrm{N}$ to $70^{\circ} \mathrm{N}$ and $25^{\circ} \mathrm{W}$ to $25^{\circ} \mathrm{E}$, with $0.5^{\circ} \times 0.5^{\circ}$ spatial resolution. In addition, daily rainfall observations from the National Weather Service of Spain (I.N.M) were obtained at each radiosonde site.

\subsection{Dynamic instability indices}

The divergence of $\boldsymbol{Q}$ vector is a direct measure of the forcing of vertical motion. In this work, $d \boldsymbol{Q}$ at $850 \mathrm{hPa}$ (d Q 850) and $500 \mathrm{hPa}(d \boldsymbol{Q} 500)\left[\mathrm{kPa} \mathrm{m}^{-2} \mathrm{~s}^{-1}\right]$ at 00:00 UTC and 12:00 UTC has been calculated as (Hoskins et al., 1978):

$$
\left(\nabla^{2}+\frac{f^{2}}{\sigma} \frac{\partial^{2}}{\partial p^{2}}\right) \omega=\frac{-2}{\sigma} \nabla \cdot \boldsymbol{Q}
$$

where $f$ is the coriolis parameter, $\omega(u, v, p, t)$ is the vertical velocity and $\sigma$ is the stability parameter.

The potential vorticity anomaly $(P V)$ can be used to track stratospheric air intrusions into troposphere and therefore atmospheric instability. $P V$ at the $330 \mathrm{~K}$ isentropic surface has been obtained by subtracting the dynamic tropopause value, defined as $2 P V$ units (Hoskins et al., 1985) [1 $P V$ unit $=10^{-6} \mathrm{~m}^{2} \mathrm{~s}^{-1} \mathrm{~K} \mathrm{~kg}^{-1}$ ]. Positive $P V$ anomalies imply an atmospheric instability increasing.

\subsection{Thermodynamic instability indices}

A great number of thermodynamic instability indices can be found in the literature. In order to target the best indicator in the study area, a stepwise regression analyses was performed. A preliminary analysis (not shown) indicated that the best characterisation can be achieved by using the Total Totals index $(T T)$, being careful with moisture level localization. $T T$ value is computed as Miller $(1967,1972)$ $T T=T_{850}+T d_{850}-2 T_{500}$, being $T$ the temperature in ${ }^{\circ} \mathrm{C}$ at the indicated levels and $\mathrm{Td}$ the dewpoint temperature.

\subsection{Method}

Instability data at 12:00 UTC and 00:00 UTC were compared with daily rainfall record to evaluate rain detection capabilities. According with climatological data, SANT shows the higher proportion of rainy days, $(43,7 \%)$, closely followed by CORU $(42,5 \%)$, LISB $(30,0 \%)$ and finally GIBR $(21,1 \%)$.

In order to classify the atmospheric instability conditions, a number of so-called "scenarios" were defined based on $d \boldsymbol{Q}$, $P V$ and $T T$ values. The probability distributions of these instability parameters were found to follow a Gaussian distribution in all stations and seasons and thus, it was possible to classify the potential instability by using percentiles as threshold levels. Dynamically unstable scenarios $(d)$ were defined as those cases with dynamical values of $d \boldsymbol{Q}$ or $P$ between a certain range of high percentile (for example p 90 and p99 for an extremely dynamical instablility). On the other hand, those situations included between a range of low percentiles (for example p15 and p25) represent dynamically stable scenarios $(D)$. To include the thermodynamic contribution the $T T$ values were considered. So, thermodynamically unstable scenarios $(t)$ were those characterised by a $T T$ value above a high percentile (p99, p95, p90, p85, p80 or p75). Cases with $T T$ value below that percentile could be 
Table 2. Percentage of rainy days recognised by the dynamical instability (d)/stability (D) scenarios at 00:00 UTC and 12:00 UTC observations.

\begin{tabular}{|c|c|c|c|c|}
\hline Station & $\begin{array}{c}\text { Total Cases } \\
\text { (RR) }\end{array}$ & $\begin{array}{l}\text { Dynam } \\
d(\mathrm{RR})\end{array}$ & $\begin{array}{l}\text { Scenarios } \\
D(\mathrm{RR})\end{array}$ & $\%$ \\
\hline CORU 00:00 UTC & 4460 & 2615 & 1628 & 95.1 \\
\hline SANT 00:00 UTC & 2073 & 1205 & 687 & 91.3 \\
\hline LISB 00:00 UTC & 1781 & 993 & 675 & 93.7 \\
\hline GIBR 00:00 UTC & 2355 & 1327 & 764 & 88.8 \\
\hline CORU 12:00 UTC & 4716 & 2746 & 1792 & 96.2 \\
\hline SANT 12:00 UTC & 2391 & 1368 & 890 & 94.4 \\
\hline LISB 12:00 UTC & 2407 & 1431 & 887 & 96.3 \\
\hline GIBR 12:00 UTC & 2306 & 1260 & 937 & 95.3 \\
\hline
\end{tabular}

classified as thermodynamically stable scenarios $(T)$. Four stability scenarios have been defined by means of thermal and dynamical components: clearly dynamically and thermally unstable $(d t)$, dynamically-unstable and thermallystable $(d T)$, dynamically-stable and thermally-unstable $(D t)$ and clearly dynamically and thermally stable $(D T)$ situations. It must be noted that obtaining the specific percentile ranges defining each instability scenario is not a trivial issue (see the Sect. 3).

Finally, the prevalent CWT during each precipitation event has been considered. The CWT is based on the dominant flow and therefore it can be used as an approach to estimate the moisture availability. This analysis is essential as precipitation will not develop or will be greatly limited if humidity sources are not available, even in cases with great dynamical instability. CWTs were characterised by means of mean precipitation rate ( $\mathrm{mm} /$ day), percentage of own days (\% days) and associated observed rainfall proportion over total precipitation amount (\% totRR).

\section{Results and discussion}

\subsection{Scenario definition}

The combined analysis of the real precipitation and the instability indices allow to optimize the specific percentile range defining the instability scenarios, yet capturing the precipitation signal. Scenario d was found to best represent the precipitation when set to the cases with dynamical indices between p95 and p75. Cases between p5 and p25 represented well a $D$ scenario. Cases with extreme dynamical stability indices (above p95 or below p5) were found to be extremely unstable in their relation with precipitation and they have not been included in the study. Likewise, scenario $t$ was found to optimally represent thermodynamic instability when set to $T T$
Table 3. Annual proportions between stability scenarios at four radiosonde stations.

\begin{tabular}{lcccc}
\hline Station & $d T$ & $D T$ & $d t$ & $d T$ \\
\hline CORU 00:00 UTC & 41.9 & 27.5 & 19.7 & 10.9 \\
SANT 00:00 UTC & 43.7 & 27.7 & 19.9 & 8.7 \\
LISB 00:00 UTC & 38.0 & 28.1 & 21.5 & 12.4 \\
GIBR 00:00 UTC & 34.3 & 24.1 & 29.1 & 12.5 \\
CORU 12:00 UTC & 39.1 & 27.5 & 21.4 & 12.0 \\
SANT 12:00 UTC & 41.1 & 30.3 & 19.4 & 9.1 \\
LISB 12:00 UTC & 38.5 & 26.0 & 23.2 & 12.3 \\
GIBR 12:00 UTC & 29.9 & 26.6 & 27.4 & 16.1 \\
\hline
\end{tabular}

values higher than p85 while $T T$ values below that threshold were found to be stable ( $T$ scenario).

As it is shown in Table 2, both dynamical scenarios, $d$ and $D,(40 \%$ of total cases) include most of the rainfall cases. Precipitation events recognised by 00:00 UTC observations are slightly lower than those shown by 12:00 UTC in all stations. Scenario d explains more precipitation events than scenario $D$. This is consistent with the main classifying criterion. Regarding thermodynamic scenarios, an average of $70 \%$ of rainy cases belong to scenario $T$ at the four studied stations, and the remaining cases (30\%) belong to scenario $t$ (not shown). Proportions between four scenarios are shown in Table 3. They follow a common pattern in CORU, SANT and LISB stations: $d T>D T>d t>D t$, both at 00:00 UTC and 12:00 UTC. Little variations from the annual pattern are found in spring (MAM) at CORU and LISB, where proportions during this season follow the order: $d T>d t>D T>D t$. GIBR station shows a different behaviour, with $d T>d t>D T>D t$ for the two daily observations. Overall, the seasonal analysis shows that dynamical instability is strengthened during spring at these stations whereas dynamical reinforcing during MAM is very subtle at SANT station.

\subsection{CWTs analyses}

In a second step, all rainy cases grouped by scenarios were classified by CWT at each season and station to test the relation between the prevalent regime and instability characteristics.

\subsubsection{Regional effects}

As an example of the regional signature of the CTW, we selected the dt scenario for MAM season since it represents the most unstable conditions. Figure 2 shows that the three westernmost stations (CORU-LISB-GIBR) present a distinct dynamical behaviour when compared to SANT. Prevalent CWT (in the sense of involving higher percentages of rainfall cases) at CORU, LISB and GIBR is the cyclonic one 

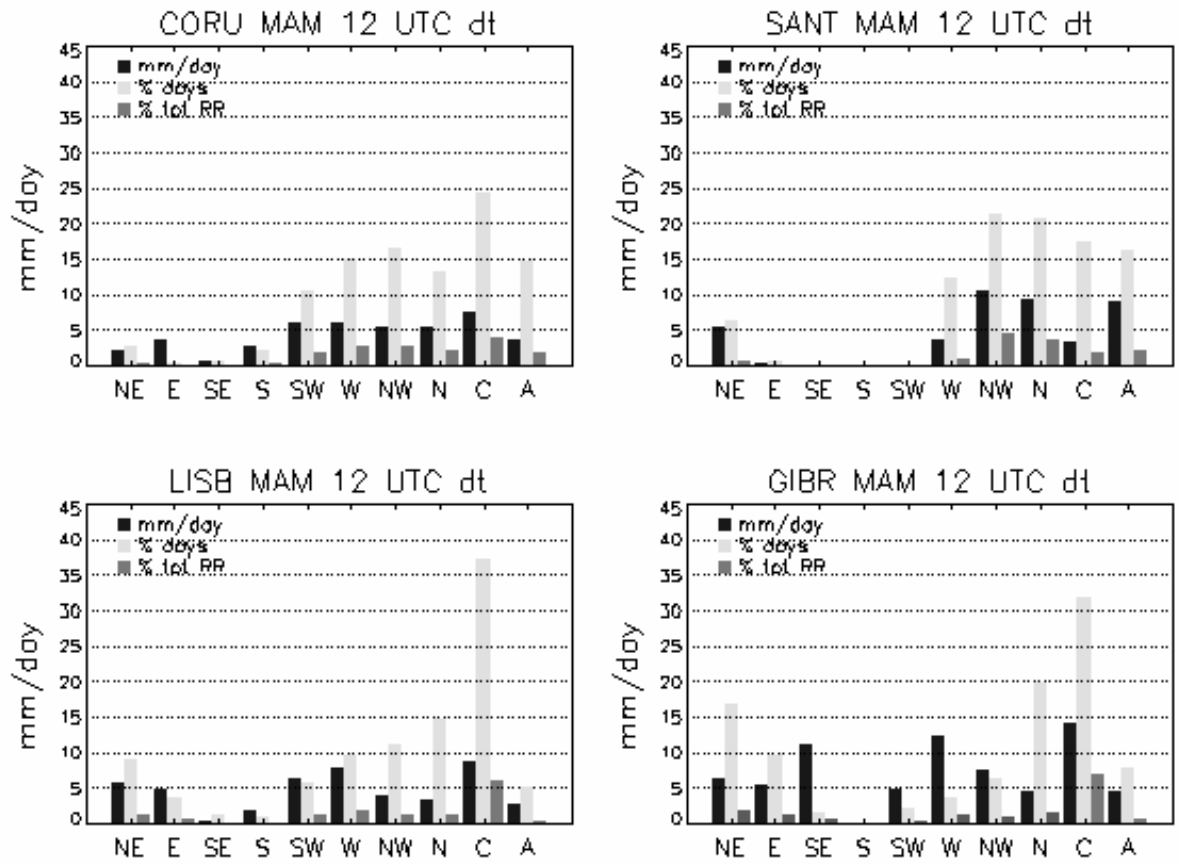

Fig. 2. Regional effects in MAM season at 12:00 UTC observation in the clerarly unstable scenario $d t$.

Table 4. Percentage of rainy cases explained by the three wettest CWTs.

\begin{tabular}{lcccc}
\hline Station & \multicolumn{3}{c}{ Wet CWTs } & \% RR \\
& C & SW & W & \\
\hline CORU 12:00 UTC & 16.4 & 14.6 & 24.4 & 55.4 \\
SANT 12:00 UTC & 7.0 & 1.3 & 10.7 & 19.1 \\
LISB 12:00 UTC & 24.1 & 14.2 & 18.1 & 56.4 \\
GIBR 12:00 UTC & 34.0 & 7.1 & 13.2 & 54.3 \\
\hline
\end{tabular}

(C) whereas NW rainfall regime is predominant at SANT station. In more detail the prevalent CWTs at each station in frequency-decreasing order are: CORU and LISB: C, W, SW, NW, GIBR: C, NE, N, W, and SANT: NW, N, A, C. Despite the higher $\mathrm{C}$ days percentage in LISB, CORU and GIBR stations present a similar dynamical rainfall pattern and they only slightly differ on small explained precipitation cuantities. On the other hand, GIBR and SANT show, as a secondary regime, northly types preference $(\mathrm{N}, \mathrm{NE})$. These results can be extended to all seasons.

In agreement with Trigo et al. (2000), the three wettest CWTs (C, W and SW) account for more than a half of the observed daily precipitation at the Atlantic facade stations. This has been found for CORU, LISB, and GIBR (Table 4) On the contrary SANT station is completely deviated from this tendency, stressing the necessity to assess the local influence.

\subsubsection{Seasonal effects}

Figure 3 shows an example of the seasonal changes in the CWTs distribution for the precipitation occurred under the dT scenario at CORU station. Since the seasonal imprint is similar, this result is largely representative of the rest of the stability scenarios. Rainy cases belonging to anticyclonic type (A) are remarkably high during all seasons. Although A is a dry CWT, there is a large number of weak precipitation events inside this group but the extremely large frequency lead to a substantial amount of rainfall. In general, mean precipitation values are usually higher in SON and DJF seasons, mainly for the C. Regarding W and SW CWTs, they are stronger in DJF, MAM and SON. Northly CWTs (N, $\mathrm{NE}$ ) are more active during JJA and MAM but despite its high frequency, they explain little of the total precipitation in these seasons. In spite of the partitioning method purposed, western Iberian rainfall regime is well supported by seasonal pattern precipitation derived from separately instability scenarios. In this regard, most rainy cases are included in SON and DJF seasons.

\subsubsection{Stability scenario-effects}

Figure 4 illustrates the differences in the precipitation distribution for LISB in autumn as a function of the prevalent stability scenario. C CWT is more frequent by far in d scenarios. Cyclonic type under dynamical instability scenarios explains more rainfall cases than $D$ scenarios. C CWT developed under a DT scenario attains the highest mean rate precipita- 

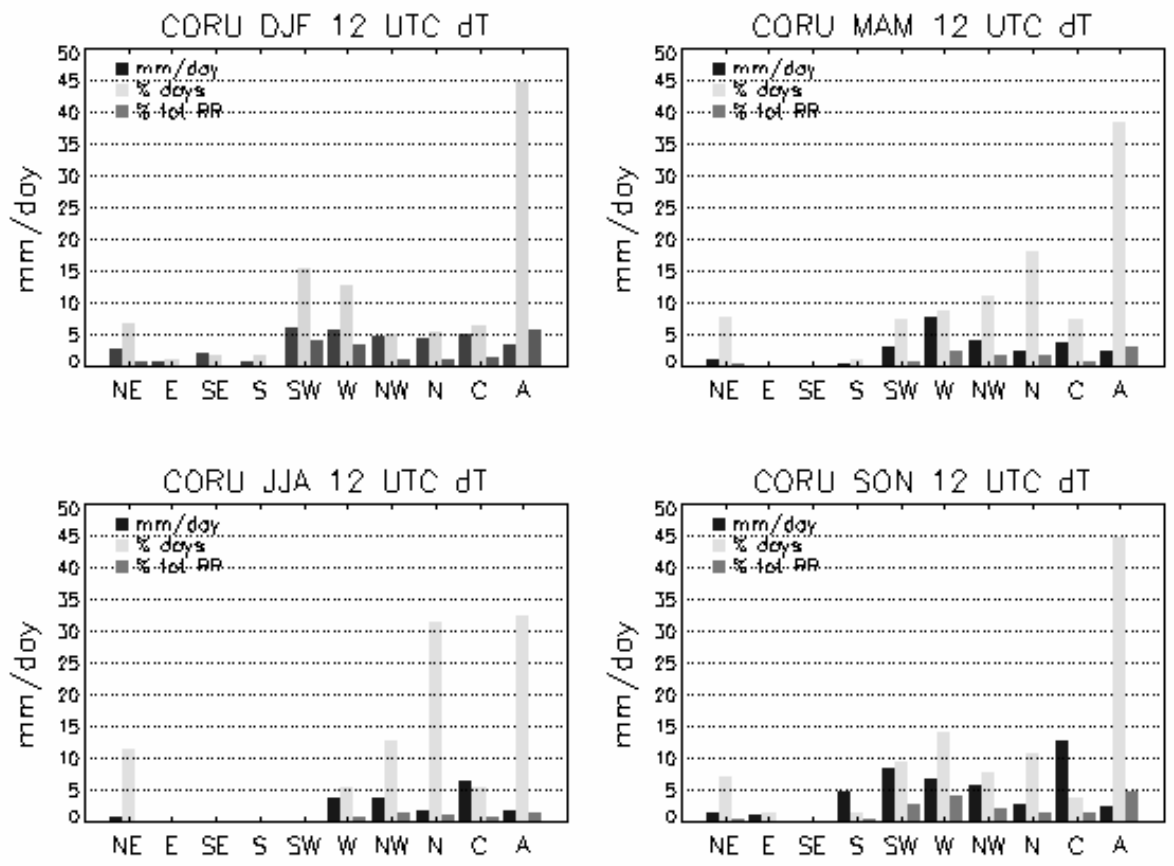

Fig. 3. Seasonal effects in CORU station at 12:00 UTC observation in the dynamical unstable scenario $d T$.
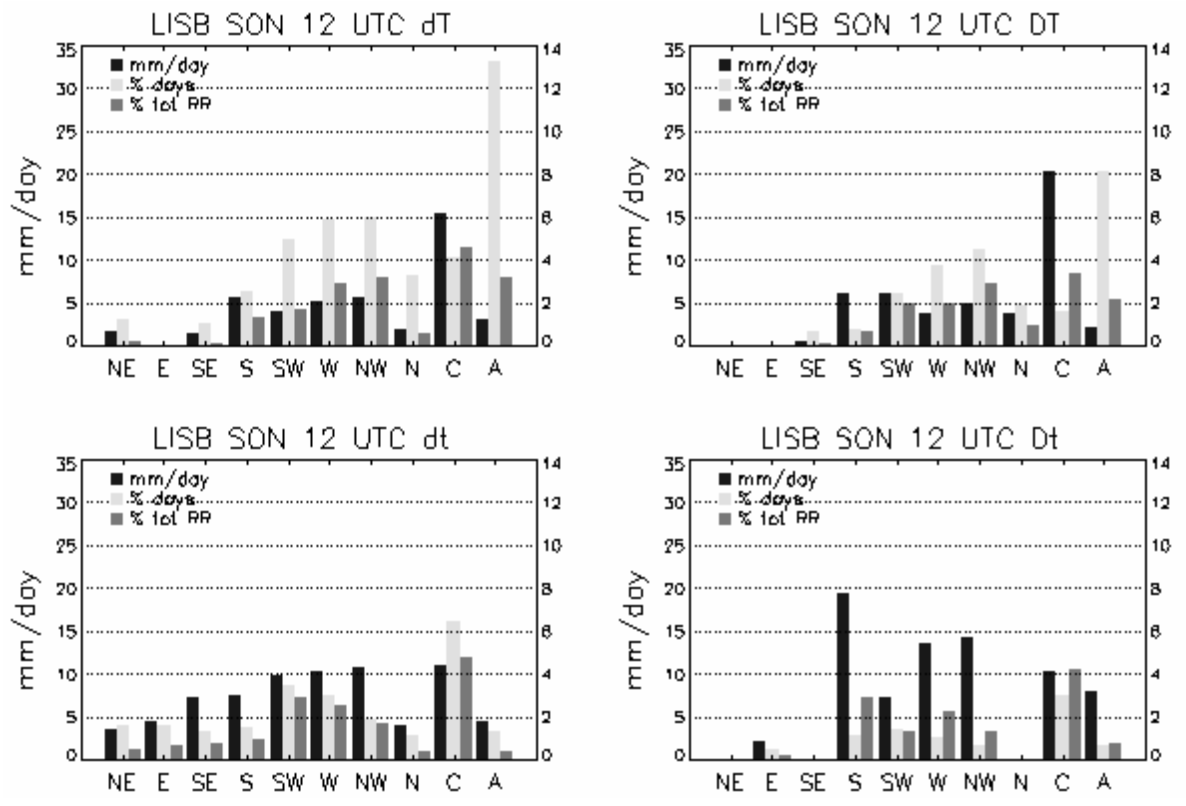

Fig. 4. Purposed stability scenarios at LISB station in SON at 12:00 UTC. Mean rate precipitation (mm/day) is referred to left axis, percentages are referred to right axis.

tion values. Regarding thermodynamic behaviour, C CWT is preferably developed under $t$ scenarios. Rainy cases in anticyclonic type (A) occurs under both $\mathrm{d}$ and $D$ scenarios, with slight preference for $\mathrm{d}$. Accordingly with the the fact that A CWT represents commonly very stable conditions, dynamical instability component in A explains more precipitation percentage than stability one does. Most of rainy A CWT cases are gathered in $T$ scenarios, that is in short dT scenario preference. W and SW CWT presented a similar pattern as C. Higher percentages of days and explained rainfall are included on dT escenario, whereas maximum mean rate precipitation value are commonly reached at $d t$ scenario. 


\section{Conclusions}

In this work we have analysed instability indices and humidity sources in order to establish preferred atmospheric instability conditions leading to precipitations over western Iberia. To define both dynamical and thermal instability features, instability thresholds have been calculated by means of percentile evaluations. The main conclusions are explained next.

In any of the proposed scenarios the study of the humidity sources availability seems essential. In this sense, the associated weather types are determinant for the occurrence of precipitation.

The combination of thermal - dynamical stability components and CWTs as approachable humidity method have been used to design proper scenarios. Most of rainy cases occur under dynamically unstable scenarios in all western Iberian stations. The situations leading to precipitation from higher to lower are $d T, d t, D T$ and $D t$.

The proposed methodology constitutes a first step in the development of an objective classification scheme of unstable conditions leading to precipitation in western Iberia. Our results reproduce the already known precipitation patterns. In addition, it seems capable of recognising the geographical variability of the frequently elusive relationship between precipitation and instability conditions.

Differences are hardly detected between 00:00 UTC and 12:00 UTC. Slightly, diurnal observations showed higher instability values, whereas 00:00 UTC observations are trended to stability values. 12:00 UTC is better for evaluating observed rainfall percentages.

Acknowledgements. The authors wish to thank U.C.M. and M.E.C for the grant and contract respectively, associated to CG04-05187CO3-01/CLI project. The authors are also grateful to I.N.M. Special thanks to S. Michaelides for all his comments and help.

Edited by: S. C. Michaelides and E. Amitai

Reviewed by: anonymous referees

\section{References}

Davis, R. E., Stanmayer, T. M., and Jones, G. V.: A synoptic climatology of tornadoes in Virginia, Phis. Geogr, 18, 383-407, 1997.

Derubertis, D.: Recent trends in four common stability indices derived from U.S. radiosonde observations, J. Climate, 19, 309323, 2006.

Durre, I., Vose, R. S., and Wuertz, D. B.: Overwiev of the Integrated Global Radiosonde Archive, J. Climate, 19, 53-68, 2006.

Dai, A. G.: Recent changes in the diurnal cycle of precipitation over the United States, Geophys. Res. Lett., 26, 341-344, 1999.

Hoskins, B. J., Draghici, I., and Davies, H. C.: A new look at the $\omega$ equation, Quart. J. R. Meteorol. Soc., 104, 31-38, 1978.

Hoskins, B. J., McIntyre, M. E., and Robertson, A. W.: On the use and significance of isentropic potential vorticity maps, Quart. J. R. Meteorol. Soc., 111, 877-946, 1985.

Kassomenos, P. A. and McGregor, G. R.: The interannual variability and trend of precipitable eater over southern Greece, J. Hydrometeorol., 7, 271-284, 2006.

Lanzante, J. R.: Resistant, robust and nonparametric techniques for analysis of climate data: Theory and examples, including applications to historical radiosonde station data, Int. J. Climatol., 16, 1197-1226, 1996.

Miller, R. C.: Notes on analysis and severe storm forecasting procedures of the Military Weather Warning Center, Tech. Rep. 200, AWS, U.S. Air Force, 94 pp, 1967.

Miller, R. C.: Notes on analysis and severe storm forecasting procedures of the Air Force Global Weather Centre, Tech. Rept. 200 (Rev.), AWS, U.S. Air Force, 102 pp, 1972.

Paredes, D., Trigo, R. M., Garcia-Herrera, R., and Franco, I.: Understanding Precipitation Changes in Iberia in Early Spring: Weather Typing and Store-Tracking Approaches, J. Hydrometeorol., 7, 101-113, 2006.

Randel, W. J. and Wu, F.: Biases in stratospheric and tropospheric temperature trends derived from historical radiosonde data, J. Climate, 19, 2094-2104, 2006.

Ross, R. and Elliott, W. P.: Radiosonde-Based Northern Hemisphere Tropospheric Water Vapor Trends, J. Climate, 14, 1602 1612, 2001.

Ross, R. and Elliott, W. P.:Tropospheric water vapour climatology and trends over North America: 1973-93, J. Climate, 9, 35613574, 1996.

Trigo, R. M. and DaCamara, C.: Circulation Weather Types and their Influence on the Precipitation Regime in Portugal, Int. J. Climatol., 20, 1559-1581, 2000.

Van Delden, A. J.: Thunderstorm predictors and their forecast skill for the Netherlands, Atmos. Res., 67-68, 273-299, 2003.

Wallis, T. W.: A Subset of Core Stations from the Comprehensive Aerological Reference Dataset, J. Climate, 11, 272-282, 1998. 